\section{Health Promotion Programs and Healthy Lifestyle: First Generation African Black Males' Perspectives}

\author{
Matthew Asare* \\ Northern Kentucky University, 111 Nunn Drive Highland Heights, KY, USA
}

\begin{abstract}
Background: It is well documented that black males are more likely to suffer from heart disease, type II diabetes, hypertension, and other chronic diseases than any other racial group in the United States. It is also undeniable fact that physical activity, healthy eating behavior, and accessing routine medical checkups can help prevent or control some of those chronic diseases. However, little is known about black African males' physical activity, nutritional and health screening behaviors in the US. Therefore, the main purpose of this study was to determine the first generation black African males' perceptions, beliefs and attitudes about healthy lifestyle and preventive care and culturally appropriate way to promote health promotion programs among them.
\end{abstract}

Methods: Convenient sample and snowball methods were used to recruit 50 (mean age $=38$ years) first generation black African males to participate in an one hour long face-to-face interview. Fifteen semi-structured open ended questions were used but there were other follow-up questions. The interview data were descriptively analyzed to find trends.

Results: The study reveals obesity and overweight problem among the participants. However, most of the participants; lead sedentary behavior, engage in poor eating habit, and do not access routine physical checkups. More than half $(n=28)$ of the participants reported that they do not do exercise or engage in physical activities because of: lack of time, laziness, lack of discipline, and lack of understanding of the importance of physical activities. Some of the participants also indicated that having a physical activity regimen is foreign to their African culture. Most of the respondents reported that they do not eat balanced diet regularly and most of their daily food intake contains too much carbohydrate. In addition, they eat similar food almost every day, skip meals which results in eating large portion size at irregular eating time. On accessing routine health screening behaviors, most respondents stated lack of trust in

*Corresponding author: Matthew Asare, Northern Kentucky University, 111 Nunn Drive Highland Heights, KY, USA, Tel: +1 8595725196; E-mail: asarem1@nku.edu

Citation: Asare M (2015) Health Promotion Programs and Healthy Lifestyle: First Generation African Black Males' Perspectives. J Community Med Public Health Care 2: 005.

Received: March 17, 2015; Accepted: May 27, 2015; Published: June 10, 2015 the healthcare system, the fear of knowing their health status, lack of health insurance were some of the reasons that prevent them from accessing regular health screening.

Conclusion: Healthy lifestyle promotion programs which are based on the culture of first generation black African males stand a better chance of having a greater impact on this targeted population as opposed to a "one-size-fits-all" approach.

Keywords: Black African males; Eating behavior; Health screening; Physical activity

\section{Introduction}

Black males (which, when the term is used in surveillance data collection in the United States (US), refers to both native born African Americans males and foreign born black males), experience disproportionately high chronic diseases such as heart disease, type II diabetes, hypertension, etc., in the United States. While the life expectancy rate gap between black males and other ethnic groups is narrowing, it must be said that + the life expectancy rate for black males is approximately six years less than other ethnic groups [1]. The Centers of Disease Control and Prevention (CDC) [2] reported that $40 \%$ of black males are more likely to die prematurely from heart disease as compared to $21 \%$ among white males. The leading causes of death among black males in the US include preventable diseases such as: cardiovascular disease, cancer (malignant neoplasms), cerebrovascular diseases, cirrhosis, chronic obstructive pulmonary disease, and diabetes mellitus [2]. Even though this study seeks to tease out first generation African black males' behaviors and perspectives about healthy lifestyles, there are no separate public health surveillance data sets on first generation black African males' health status. This is because the current methodologies for surveillance data collection consider first generation Africans and native born African Americans as a monolithic whole. There is overwhelming evidence indicating high prevalence of hypertension and elevated blood pressure [3], diabetes [4,5], obesity [6,7], and Cardiovascular diseases [8] in most African countries. Based on of the aforementioned studies in Africa, it is not far from the truth to infer that first generation African black males in the US are susceptible to getting those chronic diseases as well.

The modifiable risk factors that contribute to most of those diseases are physical inactivity, poor dietary habits and misperceptions of preventable diseases $[9,10]$. However, healthy lifestyle such as physical activity, good eating habits, and stress management can help prevent or reduce incidence of some of the chronic diseases. For instance, Physical Activity Guidelines Advisory Committee [11] in the US recommended that "for substantial health benefits, adults should do at least 150 minutes ( 2 hours and 30 minutes) a week of moderate-intensity, or 75 minutes (1 hour and 15 minutes) a week of vigorous-intensity aerobic physical activity, or an equivalent combination of moderate- and vigorous intensity aerobic activity. Aerobic activity should be performed in episodes of at least 10 minutes, and preferably, it should be spread throughout the week." Regular physical activity can help control: blood pressure, blood sugar level, lower bad cholesterol and 
increase good cholesterol, prevent type II diabetes, prevent heart diseases, and control weight. Fast walking for 15 minutes per day or slow walking for 30 minutes per day can increase physical activity behavior [12] as well as, improve ones' overall health [13]. Studies shown physical activity can improve energy expenditure [12,14], decrease the rate of type II diabetes [15], prevent heart attacks [16-18], and reduce blood pressure [19].

A healthy diet that consists of vegetables, fruits, whole grains, fat-free or low-fat milk products, seafood, poultry, lean meats, eggs, beans, peas, seeds, and nuts has been shown to promote good health. Increased consumption of fruits and vegetables can help lower the risk for heart disease and certain cancers [20,21]. The US government recommends that for each day, an adult should eat various food groups: half of daily food intake should be whole grains, and the other half should be fruits and vegetables. The recommended daily amounts of protein for adults should be between 5 and 6 ounces and dairy product food should be 3 cups for each day [22].

Regular health screening and preventive care such as physical examination, laboratory work, $\mathrm{x}$-rays, immunizations, etc., can also help early detection or prevention of an onset of certain chronic diseases. The earlier a disease is detected, the more likely it is that it can be successfully managed or treated. A study showed that preventive care such as regular screening for colorectal cancer can reduce the number of people who die from this disease in the US [23]. Ries et al., [24] reported that when colorectal cancer is detected early and treated, the 5 -year relative survival rate is $90 \%$. Again, early detection and treatment of diabetic eye disease can reduce the development of severe vision loss by $50 \%$ to $60 \%$ [25].

Over the years, efforts have been made by public health professionals to understand and help prevent some of these health problems. Their application of one-size-fits-all health promotion programs has not helped reach black males [26]. For example, studies have shown a higher physical inactivity rate among black males [27,28]. Black males have not given sufficient attention to some of the health promotion programs or preventive care programs [26-29]. However, it is unfortunate little is known about first generation African black males' physical activity, nutritional and preventive care behaviors. Therefore, the main purpose of this study was to determine the first generation black African males' perceptions, beliefs and attitudes about healthy lifestyle (physical activity and healthy eating behavior, and health screening behavior) and culturally appropriate way to promote healthy lifestyle among them. The secondary purpose of the study was to assess whether or not first generation African black males in the US meet the recommended guidelines for physical activity and healthy eating behavior.

\section{Methods}

\section{Design}

A qualitative method was used in this study to capture the lived experiences of the participants. One hour face-to-face interview was conducted among 50 first generation black African males from a large Midwestern city. Fifteen semi-structured open ended questions were used to elicit information from the participants but there were some other follow-up questions for clarifications of answers. Demographic information such as age, height and weight, country of origin, income range, marital status, educational background, and health insurance were collected during the interview. The inclusion criteria for the study were self-identified first generation African black males who were 18 years or older and expressed willingness to participate in the study.

\section{Sampling}

Glaser and Strauss [30] recommended that sample size for qualitative study should be determined by saturation point. However, Bertaux [31] on the other hand, suggested that the minimum acceptable sample size for qualitative study could be 15 participants. In the current study conscious efforts were made to recruit 50 participants from other African countries so as to gather more representative data.

\section{Recruitment process}

The participants were recruited from churches, social gathering, African grocery shops, barber shops, mechanic shops, and individual homes. Convenience sample and snowball methods were used to recruit participants because first generation black African males are very difficult to reach. The researcher personally contacted potential participants, and introduced the study to them. After interviewing each person, the researcher asked if the participant would like to refer any friends or family members to take part in the study. Upon approval and reference the researcher then contacted the referred person. This process continued until the target number of participants was obtained.

Prior to the beginning of the interview, participants who indicated their willingness to participate in the study were asked to sign informed consent. The participants were informed that the conversations would be tape-recorded, those who did not want the interview to be recorded were dropped from the study. Conscious efforts were made to protect the confidentiality of the participants by keeping all the recordings and transcripts in a locked cabinet in the researcher's office. No numbers or codes were used to identify the participants. Participants were encouraged to fully participate in the entire interview; however, they were provided an option to opt out of the study anytime they wanted. The interviews were conducted at the participant's place of choosing. Some were conducted at their work place, their homes, and others at a neutral place where they felt comfortable. Before the interview took place, permission for the study was obtained from the Institutional Review Board at the Northern Kentucky University.

\section{Data collection and analyses}

Three behaviors-namely physical activity/exercise, nutritional and accessing health screening behaviors-were evaluated. For each of the three behaviors, the overarching questions were: (a) what are the participants' current physical activity, nutritional, and health screening behaviors? (b) What are the determinants of black males' physical activity, nutritional and accessing preventive care behaviors? (c) In general, what are the participants' perceptions about black males' physical activity, nutritional and health screening behaviors? (d) Finally, what are the culturally appropriate ways to promote healthy lifestyle (physical activity or good eating habits) and preventive care (health screening) among black males? Notes were taken and the conversations were tape recorded and then transcribed. Mixed methods which includes quantitative and qualitative (trends) were used to analyze the data because the interview data were qualitative and quantitative in nature. Descriptive analyses of the demographic information were performed and the interview data 
Citation: Asare M (2015) Health Promotion Programs and Healthy Lifestyle: First Generation African Black Males' Perspectives. J Community Med Public Health Care 2: 005.

- Page 3 of 9 •

were also analyzed to find trends. To validate the findings of the interviews, four of the participants were asked to evaluate if the findings of the study represent their responses and their daily life experiences. After making few changes to study as recommended by those four participants, they found the descriptive results of the study to be acceptable.

\section{Body Mass Index (BMI)}

Obesity in this study was measured by BMI which is defined as [weight (lb)/height (in $\left.)^{2}\right]^{*} 703$. Even though, pundits have questioned the validity of using BMI as an index to measure obesity because it does not measure the lean tissue muscle, the BMI has been used as an indicator of adiposity by doctors and health care professionals over 100 years [32]. An adult with BMI below 18.5 is considered underweight, BMI from 18.5-24.96 is normal weight, BMI from 25.0-29.9 is overweight, and BMI $>30$ is considered obese [32]. Self-reported weight and height were entered into the CDC BMI calculator to compute the participants' BMI. During the interviews participants were asked about their height and weight.

\section{Results}

\section{Demographic}

Table 1, below gives detail of demographic information. Fifty first generation African black males participated in one-hour-face-to-face interviews. The minimum age of the participants was 23 years old and the maximum age 63 years old with an average age of 38 years old ( $\mathrm{SD}=10.92$ years old). In all 20 participants indicated that their country of origin is Ghana, 10 from Nigeria, seven from Togo, five from Cameroon, three from Cote d'Ivoire, two from Kenya, and other two are from Uganda. Thirty-five of the participants were married, five were divorced, and 10 were single. Majority $(82 \%, n=35)$ were employed, nine were self-employed, one was a student, and five were unemployed. More than half $(54 \%, \mathrm{n}=27)$ of the participants reported yearly income which is greater than the national poverty threshold of a family size of seven [33]. Eighteen percent $(n=9)$ of the participants are obese, 54\% $(n=27)$ are overweight, and 28\% $(n=14)$ are within the normal weight. Over $50 \%$ of the participants reported that they had health insurance while $46 \%$ participants indicated that they did not have health insurance (See table 1 for detail demographic characteristics).

\section{Participants' physical activity behavior}

Table 2, is the summary of physical activity behaviors, the range of time, and frequency of activity within a week for the participants. The majority, $78 \%(n=39)$ of the participants indicated they were physically active, while $22 \%(n=11)$ of the participants acknowledged they were not physically active at all. The participants' responses about physical activity could be generally categorized into three different groups. The first group led a sedentary lifestyle; the second group engaged in occupational activities and the third group engaged in exercise. The following response from a 41-year old participant from Ghana summarizes the participants' physical activity behaviors. "The whole of this year I have not been doing exercise. Currently, I am doing two jobs and I don't do exercise. Even though time is a factor, I still believe that because of laziness that is why I am not doing it."

In all, more than half, $56 \%(n=28)$ of the participants reported that they did not do exercise or engage in any physical activities. They also indicated that they did not have a routine time for exercise. Forty-four percent $(n=22)$ of the participants indicated that they engaged in

\begin{tabular}{|c|c|}
\hline Characteristics & Frequency $n=50(100 \%)$ \\
\hline \multicolumn{2}{|l|}{ Country of Origin } \\
\hline Ghana & $20(40 \%)$ \\
\hline Nigeria & $10(20 \%)$ \\
\hline Togo & $7(14 \%)$ \\
\hline Cameroon & $5(10 \%)$ \\
\hline Cote d'Ivoire & $3(6 \%)$ \\
\hline Kenya & $2(4 \%)$ \\
\hline Uganda & $2(4 \%)$ \\
\hline Burkina Faso & $1(2 \%)$ \\
\hline \multicolumn{2}{|l|}{ Education } \\
\hline$<$ High School & $2(4 \%)$ \\
\hline High School & $15(30 \%)$ \\
\hline Associate Degree & $8(16 \%)$ \\
\hline Undergraduate & $19(38 \%)$ \\
\hline Graduate degree or Higher & $13(28 \%)$ \\
\hline \multicolumn{2}{|l|}{ Marital Status } \\
\hline Married & $27(54 \%)$ \\
\hline Single & $16(32 \%)$ \\
\hline Divorced & $7(14 \%)$ \\
\hline \multicolumn{2}{|l|}{ Employment Status } \\
\hline Employed & $29(58 \%)$ \\
\hline Self-Employed & $12(24 \%)$ \\
\hline Student & $1(2 \%)$ \\
\hline Unemployed & $8(16 \%)$ \\
\hline \multicolumn{2}{|l|}{ Income(Yearly) } \\
\hline Zero & $8(16 \%)$ \\
\hline below 20,000 & $3(6 \%)$ \\
\hline $20,001-40,000$ & $12(24 \%)$ \\
\hline $40,001-50,000$ & $13(26 \%)$ \\
\hline Above 51,000 & $14(28 \%)$ \\
\hline \multicolumn{2}{|l|}{ BMI } \\
\hline Underweight $<18.5$ & $0(0 \%)$ \\
\hline Normal 18.5-24.9 & $14(28 \%)$ \\
\hline Overweight 25.0-29.9 & $27(54 \%)$ \\
\hline Obese $>30$ & $9(18 \%)$ \\
\hline \multicolumn{2}{|l|}{ Health Insurance } \\
\hline Yes & $27(54 \%)$ \\
\hline NO & $23(46 \%)$ \\
\hline Mean Age $=38$ years $(\mathrm{SD}=10.92$ years $)$ & \\
\hline
\end{tabular}

Table 1: Demographic characteristics of the participants $\left(n^{*}=50\right)$.

\section{${ }^{*} \mathrm{n}=$ number of participants}

physical activities or exercise. Out of the $44 \%(n=22)$ participants who did exercise, $32 \%(n=16)$ of them said they participated in more than 
one form of physical activities in a given week. In all $22 \%(\mathrm{n}=11)$ participants reported having a routine schedule for exercise. For instance, $12 \%(\mathrm{n}=6)$ of the participants indicated that they walked between 15 minutes to 60 minutes each day, between one to five days a week (Table 2). About $10 \%(n=5)$ reported running more than 30 minutes, between one to three days a week and the other $16 \%(n=8)$ spent 25 to 90 minutes weight lifting for three days.

Organized sport, such as soccer, was reported as one of the popular sporting activities in which the participants engaged. A total of $10 \%$ $(n=5)$ of the participants said they played soccer for at least 90 minutes once a week. Two participants said they played soccer, however, they did not engage in soccer on a regular basis and at times, they only played soccer for 25 minutes to 90 minutes once in a month.

Three of the participants said they engaged in occupational activities, which included: walking, lifting things from one place to another, and gardening. (See table 2 , for summary of physical activity behaviors). The most common reasons given by the participants for engaging in physical activities include, fun, physical fitness, to stay in good shape, reduce weight, and also to reduce stress. However, five of the participants indicated they exercised because of their current health situation and that their doctors asked them to exercise. The results of the study also revealed that the overwhelming majority (over $90 \%$ ) of the participants did not meet the physical activity committee [11] recommended guidelines for adults engaging in at least 30 minutes of moderate-intensity aerobic activity for 5 days per week for a total of 150 minutes. However, three participants who indicated that they engage in occupational physical activities exceeded the said recommendations.

\begin{tabular}{|c|c|c|c|}
\hline Description & Participants & Amount of time & $\begin{array}{l}\text { Frequency } \\
\text { (week) }\end{array}$ \\
\hline No physical activity & 28 & N/A & $\mathrm{N} / \mathrm{A}$ \\
\hline Job related activities & 3 & 30 minutes- 3600 minutes & 2 days -5 days \\
\hline Running/jogging ${ }^{1}$ & 5 & 10 minutes- 60 minutes & 1 day- 3 days \\
\hline Walking $^{1}$ & 6 & 15 minutes- 60 minutes & 1 day- 4 days \\
\hline Sports (soccer) & 5 & 25 minutes- 90 minutes & 1 day \\
\hline weight lifting ${ }^{2}$ & 8 & 25 minutes-90 minutes & 1 day- 3 days \\
\hline Push up/Press up ${ }^{2}$ & 5 & 15 minutes- 30 minutes & 2 days -7 days \\
\hline Swimming & 2 & 25 minutes- 30 minutes & 2 days -3 days \\
\hline
\end{tabular}

Table 2: Summary of physical activity behaviors, the range of time, and frequency of activity within a week for the participants $(n=50)$.

${ }^{1}$ Participants who reported running/jogging said they also do walking

${ }^{2}$ Those who reported they do push up also reported that they do weight lifting

\section{Reasons for physical inactivity}

The reasons gleaned from the participant responses for sedentary behavior include: cultural influence, lack of time, the safety concerns in their neighborhood, laziness, lack of discipline, and lack of understanding of the importance of physical activities. All the participants admitted that by nature Africans are physically active because their daily lives revolve around physical activities. Several participants indicated that an average African walks more than one mile daily. Back in Africa most people don't make a decision or plan to engage in physical activity for the purpose of their health. They do it because it is a necessity. However, some of the participants believed that that kind of cultural influence has contributed to the black males' physical inactivity in the US. One Nigerian participant succinctly described the cultural influence on black males' physical inactivity behavior in the US this way: "It is very difficult to get into a routine exercise, especially for black males. Most of the time exercise has to do with discipline... we have a culture of doing physical activities, but I believe this cultural influence has affected black males in the US in a negative way. This is because when we came to the US everything is opposite. You wake up in the morning and jump into your car, go to work, and you come back home. At times you work two or three jobs and you don't have time for anything and that has become a lifestyle. We are no longer living that physical activity lifestyle any more. That means that if you want to engage in physical activities, you have to plan your schedule well, be committed and disciplined. Unfortunately, most blacks don't want to add that kind of burden on their already stressful lifestyle."

With regards to time, many of participants said most black African males have a lot of responsibilities in the US, as well as, in Africa. They argued that black males have the same responsibilities of paying their bills as everybody does have in the US; however they have other responsibilities of taking care of their families back in Africa. As a result, they end up working more than one job to be able to meet all of the obligations; therefore exercise is the last thing on their mind.

The participants identified lack of access to physical activity facilities, expensive gym membership fees, the weather (cold and humid weather), and safety concerns as some of the environmental factors that prevent them from engaging in physical activities. Some of them said "winter is too cool, and summer is too humid for them to exercise."

Concerning the issue of safety, many of the participants believed that some of their neighborhoods are not safe to do exercise outdoors. They acknowledged that in most cases it is not safe for everybody, irrespective of your race or ethnicity. However, a few of the participants believed that being an African exposes them to more dangers. They were quick to compare their experiences in Africa to how they see things in the US. A seventy year old Nigerian retired college professor stated: "In Africa you don't only know your neighbors full name but also you know their children's name to the extent that you know the members of extended family. You can just walk to them, knock on their door without giving them a prior notice and play all kinds of outdoor games in the neighborhood without any fear for your safety. But here you need to be extra careful because you hardly know your next door neighbor. You meet your neighbor once in a while and at times the best you can do is just say 'hi' and that is it. You are always scared to take a walk in your neighborhood because you are not sure about other person's perception about you."

\section{Participants healthy eating behavior}

Almost all the participants, 94\% $(n=47)$ reported that they had a healthy eating behavior. Many of participants, $90 \%(n=45)$ stated that they preferred to cook their own traditional African food. However several of them, about $56 \%(n=28)$, admitted that once in a while they eat fast food, especially when they are away from home for a long time. The participants reported eating major food groups such as fruits, vegetables, grains, and proteins. For fruits, the most common ones among the participants were bananas, apples, oranges and watermelon. Among the vegetables the participants mentioned most were carrots, broccoli, spinach, and corn. Participants mentioned brown rice, wheat bread, and white rice, as some of the examples of daily grain food they normally eat. Many of the participants also said they eat a lot of beans and smoked fish.

One of the common traditional African foods they mentioned included fufu (prepared from powdered yam, cocoyam, cassava or 
plantain) with soup (prepared with vegetables). They also mentioned plantain, yam, rice, banku (prepared from corn dough), kenkey (also made from corn dough but has a plantain leaf wrapper on it), eba (made from cassava flour), ugali (made from maize flour), maize, millet, and beans as some of the traditional food they eat in the US.

When the question: "Do you check for the nutritional components of the food you eat?" was asked, about $80 \%(n=40)$ of the participants reported they did not check for the nutritional components, because culturally most of the food they eat does not have food labels. They reported eating the same kind of food since they were born and therefore they saw no reason to bother themselves to check for the nutritional labels. A participant stated, "No I normally don't check. This goes back to our culture because we don't check for the nutritional components. We also don't have the means to check for the nutritional component because there are no food labels so we don't check it."

A few of the participants, about $60 \%(n=30)$, indicated that they did not know the nutritional components of the food they eat. One participant stated: "I don't check for the nutritional components of the food I eat and I believe most black African males do not check for them because their parents introduced them to the food and they believe it has the requisite nutrients they need. I don't know anything about nutritional components, I just eat what my mother introduced to me and I believe they are healthy food too."

When the question: "How often do you consume high fat foods and trans fats (i.e., donuts, butter, fried foods, and fatty red meats) on a normal day?" was asked, many of the participants were quick to indicate that they hardly ate high fat foods or food with trans-fat. Even though almost all the participants indicated that they did not eat high fat food, $50 \%(n=25)$ of the participants said they ate some kind of fried food such as french fries, fried yam, fried rice, fried chicken, and fried ripe plantain regularly. They also indicated they ate most of the food with stew (mixture of vegetables and meat usually prepared with oil). About $30 \%(n=15)$ of the participants indicated that they drunk between two to four glasses of water every day, $52 \%(n=26)$ said five to seven glasses of water, and $18 \%(n=9)$ reported eight or more glasses of water every day.

The participants indicated that the problems they face in getting or eating traditional African food in the US included: the amount of time needed to prepare traditional food; the cost of African food; and the lack of availability of diverse organic African traditional food. One Nigerian participant stated "The food in African is different, they are organically produced and in most cases you don't get them here in the US. The available African or tropical food in the US is so expensive to buy. Also at times it takes a long time to cook African food." Some of the participants reported that they don't like most of the American food. Overall, most of the participants identified the large portion size of the food, the high dense carbohydrate food, fried food, failure to eat three square meals and eating the same kind of food most of the time as a concern for black males from Africa.

\section{Health screening behavior}

Majority, 54\% ( $\mathrm{n}=27)$, of the participants stated that they did not access health screenings for conditions such as hypertension, hypercholesterolemia, cancer, diabetes, etc. However, $42 \% \quad(n=21)$ indicated they accessed health screenings at least once a year and another $4 \%(\mathrm{n}=2)$ said they used to access health screenings regularly when they had health insurance. Interestingly, among those who access health screening regularly, about $71 \%(n=15)$ of them have known health problem(s) and that accounts for the reason why they went for checkup. Unfortunately, the participants who used to access health screening or preventive health care indicated that they have known health problems, but because they did not have health insurance they have not been seeing their doctors regularly. One of them said he did monitor his blood pressure and also did self-medication by taking over-the-counter medications to control his health condition.

Some of the reasons the participants gave for not accessing health screening and preventive care include: their culture and their belief system; lack of trust in the health care system; the fear of knowing their health status; expensive health care; lack of insurance; ignorance and problems of navigating American health care system; and the use of alternative medicine such as traditional/herbs. For instance, a 40-year old Ghanaian participant had this to say about the black males' culture and belief system: "No, I don't regularly access health screening or preventive care because I don't have any health problem and it is too expensive. I haven't gone for checkup since I came to the US about six years ago but I am still healthy. When I wake up and I feel good, I just thank my God and move on with my life."

\section{Discussion}

The purpose of the study was to determine the first generation African black males' perceptions, beliefs, and attitudes about healthy lifestyle, health screening or preventive care, and culturally appropriate ways to promote health promotion programs among them. The study also assessed if first generation African black males in the US meet the recommended guidelines for physical activity and healthy eating. The BMI results of the study did not only confirm obesity and overweight problems among first generation black African males [34,35] but also they revealed disturbing potential health problems for three reasons: First, most of the participants were physically inactive and with $18 \%$ of the participants being obese and over $54 \%$ being overweight, they are at risk of experiencing hypokinetic diseases. Second, since some of the participants did not want to access health screening, they might not know their health status whether or not they have any hypokinetic diseases for which they may need either early treatment or preventive care before the disease progresses to an advance stage. Finally, the poor eating behaviors of the participants may compound their health problems.

The study showed that most of the first generation black African males lead sedentary lifestyle and this lends credence to conclusions drawn by Jones et al., and Marshall et al., $[27,28]$ that black males are physically inactive. The study also revealed that the overwhelming majority of the participant did not meet the physical activity committee [11] recommended guidelines for adults engaging in physical activity. The findings are consistent with Sahrif et al., [36] study that there is a high degree of acceptance of physical activity among first generation black African males but they sometimes mistakenly express physical activity only in terms of sporting activities. It could be one of the reasons why most of the participants indicated that they do not have enough time to participate in physical activities. Obviously, all the sporting activities demand some amount of time. So equating physical activities to sports could definitely discourage people from engaging in physical activity. It is therefore imperative to educate first generation black African males, first about time management and second about the fact that physical activity is not always the same as sporting activities and that a 30-minute brisk walking per day can improve upon their health status. 
The study also revealed a subtle contradictory belief system among first generation African black males about their physical activity behaviors. In other words, the participants believe that they are physically healthy because of their past experience and their culture of being physically active in Africa, but when they were asked to critically reflect on their current physical activity behavior in the US, they realized that there is a gap between their past experience and their current behavior. It is not because they are lying or being deceptive about their physical activity behavior but they are simply oblivious to the fact that their current environment and lifestyle are gradually contradicting their ingrained belief system that Africans are physical active. Therefore, health professionals who are dealing with first generation African black males should not take it on the face value when they claim that they are physical active. Health professionals should probe very well into what they mean "by being physically active."

The study also confirmed that environmental factors such as weather (extreme cold and hot weather), accessibility to physical activity facilities, safety concerns, convenience etc., contribute to sedentary lifestyle. Even though it is true that those environmental factors are problem for everybody in the US, it is more serious problem for first generation African black males. This is because they grew up in an environment where most of those factors were less of a problem to them. They could turn any open space as a playground and did not have to worry so much about cold weather or extremely hot weather, or safety concerns. The problem among first generation African black males in the US is worsened by convenience and easy accessibility to cars, and the fact that they are not oriented toward the culture of regime exercise and gym membership. While in their respective countries in Africa, the participants were very active, it is so unfortunately that most of them did not associate their active lifestyles to healthy living. Some of them saw those active lifestyles as necessity i.e., the only means to move from one place to another or survived, while others saw it as a lifestyle full of struggles. So when they moved to the US, they are trapped in the convenient lifestyle and they see it as a dream comes true. For some of them, any suggestion to do exercise, for example, go for a walk, may seem like asking them to go back to their former struggling lifestyle. It is therefore important to refocus first generation African black males' attention to the health benefits that come with engaging in physical activity.

The study found that first generation African black males did not meet the daily recommended guideline for eating the major food groups (whole grains, vegetables, fruits, proteins, and dairy). The participants' responses showed that they have tendency to eat similar type of food almost every day. For example, some of the participants indicated fufu or rice form greater percentage of their daily food and that they hardly eat different food groups as recommended. This eating behavior goes back to the African culture where staple food for dinner, for instance, is always a similar kind of food for most people. Having said that, it must be added that, as the study revealed, most first generation African black males eat various food groups like grains, fruits, vegetables, and proteins but they do not make conscious decision to eat balanced food daily. For instance, they eat fruits as to when they feel like eating and for the most part the emphasis is on taste or/and on getting full and not worrying so much about obtaining right amount of various nutritional values. Effort should be made to educate first generation African black males to eat balanced diet instead of eating similar food almost every day. The study showed that the first generation African black males relish the idea that they used to eat healthy food in Africa and that they continue to eat traditional African food in the US. Those findings of the current study support Oniango, Mutuku, and Malaba, [37] assertion that "Food habits are slow and difficult to change because food has important psychological associations with the family and the community. Familiar food is satisfying and reassuring, particularly the traditional foods of childhood, which evoke a deep-seated emotional response."

Since food evokes emotion, has psychological association, and is culturally driven, it is important for health professionals to know and understand eating behavior and the types of food first generation African black males eat before they offer any suggestions to change their eating behaviors. As one participant bluntly puts "I eat what my mother gave to me when I was growing up and I know it is good so I don't need to know what it contains and I don't need to change anything." Therefore to influence such an individual's eating behavior, efforts should be made to understand the person's culture.

Another eating behavior about the participants in the study worth discussing is the amount of portion size the participants eat. The concern with first generation African black males eating behavior is that most of them do not follow any defined mealtime and/or they skip meals. Consequently, they tend to eat large portion size to make up for whatever they lost and that eaten behavior had been found to be unhealthy [38]. Some of the participants' behaviors of skipping meals and not following regular meal time are commonplace in most African countries because of poverty some cannot afford three square meals and having regular meal time are not part of some African culture. Finally, another eating behavior that the study reveals about African black males is that greater percentage of the meal is made up of carbohydrate. They also use trans-fat or saturated fat in preparing most of their food. Study has found that eating food prepared with trans-fat is not good for one's health [39] but unfortunately the current study shows that first generation African black males eat a lot of fried food prepared with saturated fat and at times trans-fat.

The result of the study indicates that most of the participants do not access routine health screenings. This finding is consistent with similar conclusions drawn by Chokunonga et al., [40] that most Africans do not access health screening and it is not a common practice for most people in Africa to access health care checkups. The current study results also support Frost's study [41], in most cases an African will go to see a doctor or go to a hospital only when he is seriously ill. At best an African will buy an over-the-counter medicine to treat himself or will use traditional medicine. This study reveals that some of the participants still rely on traditional medicines for their health care regimen. The concept of somebody going for physical examination is not a common practice in most African countries. This behavior continues for most black African males who have migrated to the US, as the study reveals. Some of the African males in the study are suspicious about American health care system because most of them believe the health care system is not fair to them. One participant said, "there is an unspoken belief among Africans in the US that so long as you are black and have accent you will not receive proper attention from healthcare professionals as would a white person receive." This kind of mistrust is difficult to explain but believe it or not it discourages some first generation African black males from accessing health screening or health care in general. Many of the participants do not want to know their health status, because of the fear of the unknown.

Limitations: The first limitation of the study is the method of recruitment. The use of snowball methods may skew the responses to 
a particular group of people. Since the researcher relied on personal contacts and referrals, the participants may not be representative enough and this may account for the reason why most of the participants were Ghanaians. Future studies should strive to include more other nationalities to make the study representative. Second, time factor was another limitation on this study. Since the interview time lasted for one hour, some of the participants decided not to take part in the study because they indicated that they did not have time to be interviewed even though they were willing to participate in the study.

Third, the study relied only on personal accounts, honesty, and integrity of the participants since there were no means to verify the truthfulness or inaccuracies of the information provided. Nevertheless, the accurateness of the information provided by the participants was to a greater degree validated by the uniformity of the answers provided by the respondents. Fourth, the study was predicated on the assumption that the first generation African black males have the same culture but in reality there are cultural differences across the African continent and within each African country. For instance, the type of food produced in West Africa is different from the food produced in East Africa [37]. However, the study tried to piece together the commonalities among African culture. Future studies can be done separately based on where in Africa participants are from originally: West Africa, East Africa, North Africa or Southern Africa.

The use of BMI has limitations. First, BMI can overestimate or underestimate the "fatness" of very tall or very short people, as well as underestimate "fatness" in those with a small amount of muscle mass (or lean mass). Second, there is a potential problem with the participants reporting their weight and height. Height can decrease in older age, due to spinal changes. Additionally, often overweight people do not weigh themselves frequently (unless they are trying to lose weight).

Finally, the dearth of scientific studies about first generation African black males' healthy lifestyle in the US made it difficult to support or refute the findings of the current study. Since this study is exploratory in nature, it brings to the forefront an aspect of minority health which has long been neglected. More studies need to be done on diverse and larger African population to verify the validity of the results of this study.

Implications for practice: Notwithstanding the above limitations, this research study contributes to the understanding of first generation African black males' physical activity, nutritional and health screening behaviors in the US. The first implication is most of the participants are either being obese or overweight. Yet, most of them lead sedentary lifestyles, have the tendency to engage in unhealthy eating behaviors, and do not want to access health screenings. Therefore, health professionals should continue their efforts to educate first generation African black males. The study reveals that the majority $90 \%(n=45)$ of the participants recommended that black males should be reached with more educational programs. The participants indicated that health educational programs targeting African black males should focus on:

- Importance of physical activity, vis-à-vis physical inactivity

- Emphasis on physical activity as a preventive mechanism, not only as a means to cure diseases

- Time management
- Promoting group physical activity through sporting activities like soccer, running, marathon

- Nutritional components of Blacks' traditional food

- Reduction of Carbohydrate (Starchy) food

- The need to eat balanced diet

- The need to reduce portion size

- The need to reduce trans-fat and saturated fat used in preparing food

- Importance of health screening and preventive care

Second implication for practice is that health professional working with African black males should build trust among African black males. To build trust, the participants recommended that health professional should be culturally competent, be a role model, and knowledgeable about their profession. For instance, majority of the participants (over 60\%) indicated they can trust somebody who is culturally competent to implement educational programs in black community.

The third implication is that the participants' physical inactivity behaviors, poor eating habits and avoidant health screening behaviors were shaped by their respective cultural backgrounds. Having a better understanding of those cultural influences can help the health professional to develop targeted educational programs.

Policy implications: The findings of the study revealed that policy makers can provide incentives such as free gym membership so as to promote physical activity among first generation black males. Concerns for neighborhood safety means that more efforts should be made by community members and policy maker to promote safety in their neighborhood. The traditional African food should be required to have food labels on the imported tropical food. Incentives and resources should be made available to promote health screening at relatively low cost so that those who do not have health insurance can continue to access early health screening.

Summary: Chronic diseases are prevalent among black males but physical activity, healthy eating behavior and regular health screening can help control some of those chronic diseases. However, little is known about first generation African black males' physical activity, eating behaviors, and health screening behaviors. Therefore, after the protocol of the study was approved by Northern Kentucky University Institutional Review Board, face to face interviews were conducted among 50 first generation black males to elicit information about first generation black males' physical activity, eating and health screening behaviors. The study reveals that most of the participants reported sedentary behavior. The majority of participants indicated they prepared African food in homes but they have unhealthy eating behaviors. They indicated that preventative care is expensive and the fear of knowing their health status deters them from accessing preventive care. They indicated health professionals, who have a better understanding of their culture; their food; and also lead healthy lifestyle themselves, are the professionals they trust for health promotion programing.

In conclusion, traditionally most first generation African black males had been exposed to and experience daily physical activity in their respective African countries. Due to the convenient lifestyle and environmental factors in the US, most of them are now leading sedentary lifestyles. On healthy eating, the first generation African black males' eating behaviors in the US are still rooted in their 
Citation: Asare M (2015) Health Promotion Programs and Healthy Lifestyle: First Generation African Black Males' Perspectives. J Community Med Public Health Care 2: 005.

traditional and culture upbringing. With respect to accessing routine health screening behavior, African black males are struggling to come to terms with this behavior, because it is a new culture to them. It is important for health care professionals to better understand black's native culture and their food culture. This will aide in the development of trust for African black males for health promotion programs. Healthy lifestyle promotion programs which focus on first generation African black males' culture stand a better chance to have a greater impact with this targeted population as opposed to a "one-size-fits-all" approach.

\section{References}

1. Arias E (2012) United States life tables, 2008. National vital statistics reports. National Center for Health Statistics, Hyattsville, MD, USA, 61: 1-64.

2. National Center for Health Statistics (2012) Health, United States, 2011: With Special Feature on Socioeconomic Status and Health. Centers for Disease Control and Prevention, Hyattsville, MD, USA.

3. Hendriks ME, Wit F NM, Roos MTL, Brewster LM, Akande TM, et al. (2012) Hypertension in sub-Saharan Africa: Cross-sectional surveys in four rural and urban communities. PLoS One 7: 32638.

4. Dzudie A, Kengne AP, Muna WF, Ba H, Menanga A, et al. (2012) Prevalence, awareness, treatment and control of hypertension in a self-selected sub-Saharan African urban population: a cross-sectional study. BMJ open 2: 001217

5. Dalal S, Beunza JJ, Volmink J, Adebamowo C, Bajunirwe F, et al. (2011) Non-communicable diseases in sub-Saharan Africa: what we know now. Int J Epidemiol 40: 885-901.

6. World Health Organization (2010) International comparisons: Estimated overweight \& obesity $(\mathrm{BMI}>25 \mathrm{~kg} / \mathrm{m} 2)$ prevalence, females, aged $15+$. WHO Global InfoBase, Geneva, Switzerland.

7. Wand H, Ramjee G (2013) High prevalence of obesity among women who enrolled in HIV prevention trials in KwaZulu-Natal, South Africa: healthy diet and life style messages should be integrated into HIV prevention programs. BMC Public Health 13: 159

8. Etyang AO, Scott JA (2013) Medical causes of admissions to hospital among adults in Africa: a systematic review. Glob Health Action 6: 1-14.

9. Godino JG, Lepore SJ, Rassnick S (2010) Relation of misperception of healthy weight to obesity in urban black men. Obesity (Silver Spring) 18 1318-1322.

10. Bennett GG, Wolin KY (2006) Satisfied or unaware? Racial differences in perceived weight status. Int J Behav Nutr Phys Act 3: 40.

11. Physical Activity Guidelines Advisory Committee (2008) Physical Activity Guidelines Advisory Committee Report. Washington: Department of Health and Human Services, USA

12. Morabia A, Costanza MC (2004) Does walking 15 minutes per day keep the obesity epidemic away? Simulation of the efficacy of a population wide campaign. Am J Public Health 94: 437-440.

13. Corbin C, Welk G, Corbin W, Welk K (2010) Concepts of lifetime fitness: A Comprehensive Lifestyle Approach. McGraw Hill, Learning Solutions, Boston, USA.

14. Jeffery RW, Wing RR, Sherwood NE, Tate DF (2003) Physical activity and weight loss: does prescribing higher physical activity goals improve outcome? Am J Clin Nutr 78: 684-689.

15. Knowler WC, Barrett-Connor E, Fowler SE, Hamman RF, Lachin JM, et al. (2002) Reduction in the incidence of type 2 diabetes with lifestyle intervention or metformin. N Engl J Med 346: 393-403.

16. Yusuf S, Hawken S, Ounpuu S, Dans T, Avezum A, et al. (2004) Effect of potentially modifiable risk factors associated with myocardial infarction in 52 countries (the INTERHEART study): case-control study. Lancet 364: 937952.
17. Snell PG, Mitchell JH (1999) Physical inactivity: an easily modified risk factor? Circulation 100: 2-4

18. Wei M, Kampert JB, Barlow CE, Nichaman MZ, Gibbons LW, et al. (1999) Relationship between low cardiorespiratory fitness and mortality in normal-weight, overweight, and obese men. JAMA 282: 1547-1553.

19. Stewart KJ (2002) Exercise training and the cardiovascular consequences of type 2 diabetes and hypertension: plausible mechanisms for improving cardiovascular health. J Amer Med Assoc 288: 1622-31.

20. McGuire S (2011) US Department of Agriculture and US Department of Health and Human Services, Dietary Guidelines for Americans, 2010. 7th Edition, Washington DC: US Government Printing Office, January 2011. Adv Nutr 2: 293-294.

21. CDC. Fruits and vegetables benefits.

22. Myplate: Food groups. United States Department of Agriculture, VA, USA..

23. US Preventive Services Task Force (2008) Guide to clinical preventive services. Agency for Healthcare Research and Quality, Rockville, MD, USA.

24. Ries LAG, Melbert D, Krapcho M, et al. (2008) SEER Cancer Statistics Review, 1975-2005. National Cancer Institute, Bethesda, MD, USA.

25. Kung HC, Hoyert DL, Xu J, Murphy SL (2008) Deaths: final data for 2005. Natl Vital Stat Rep 56: 1-120.

26. Sanders Thompson VL, Talley M, Caito N, Kreuter M (2009) African American men's perceptions of factors influencing health-information seeking. Am J Mens Health 3: 6-15.

27. Jones DA, Ainsworth BE, Croft JB, Macera CA, Lloyd EE, et al. (1998) Moderate leisure-time physical activity: who is meeting the public health recommendations? A national cross-sectional study. Arch Fam Med 7: 285-289.

28. Marshall SJ, Jones DA, Ainsworth BE, Reis JP, Levy SS, et al. (2007) Race/ ethnicity, social class, and leisure-time physical inactivity. Med Sci Sports Exerc 39: 44-51.

29. Cheatham CT, Barksdale DJ, Rodgers SG (2008) Barriers to health care and health-seeking behaviors faced by Black men. J Am Acad Nurse Pract 20: 555-562.

30. Glaser B, Strauss A (1967) The discovery of grounded theory: Strategies for qualitative research. Aldine Publishing Company, New York, USA.

31. Bertaux D (1981) From the life-history approach to the transformation of sociological practice. In Daniel B (eds.). Biography and society: The life history approach in the social sciences. Sage, London, UK.

32. US Census Bureau (2014) Social, Economic and housing statistics division: Poverty threshold.

33. CDC (2013) Healthy weight - it's not a diet, it's a lifestyle! Centers for Disease Control and Prevention, GA, USA.

34. Ogden CL, Lamb MM, Carroll MD, Flegal KM (2010) Obesity and socioeconomic status in adults: United States 2005-2008. NCHS data brief no 50 National Center for Health Statistics, Hyattsville, MD, USA.

35. Commodore-Mensah YY, Agyemang CO, Aboagye J K, Abu-Bonsrah N, Himmelfarb CR (2014) The AFRO-CardiAC study: Assessing the Cardiovascular Disease Risk among West African Immigrants in the USA.

36. Sahrif S, Cooper C, Verma C (1997) Guidelines: Promoting physical activity with black and minority ethnic groups. Health Authority Group, London, UK.

37. Oniang'o RK, Mutuku JM, Malaba SJ (2003) Contemporary African food habits and their nutritional and health implications. Asia Pac J Clin Nutr 12: 331-336.

38. Carlson O, Martin B, Stote KS, Golden E, Maudsley S, et al. (2007) Impact of reduced meal frequency without caloric restriction on glucose regulation in healthy, normal-weight middle-aged men and women. Metabolism 56: 17291734.

39. Mozaffarian D, Aro A, Willett WC (2009) Health effects of trans-fatty acids experimental and observational evidence. Eur J Clin Nutr 63: 5-21. 
Citation: Asare M (2015) Health Promotion Programs and Healthy Lifestyle: First Generation African Black Males' Perspectives. J Community Med Public Health Care 2: 005.

- Page 9 of 9 •

40. Chokunonga E, Borok MZ, Nyakabau AM (2003) Patterns of cancer in Zimbabwe: Zimbabwe National Cancer Registry Annual Report.
41. Frost O (1981) Some aspects of the problem of carcinoma of the cervix in Zimbabwe. Cent Afr J Med 27: 169-171. 